Check for updates

1 Cochrane Sustainable Healthcare

2 London, UK

minna.johansson@vgregion.se Cite this as: $B M J 2020 ; 371: \mathrm{m} 4544$ http://dx.doi.org/10.1136/bmj.m4544 Published: 23 November 2020

\section{Can covid-19 help us deal with the pandemic of defensive medicine?}

\author{
The threat of the virus has made us take a step back and critically reflect on our priorities and our \\ actions
}

Minna Johansson, ${ }^{1}$ Iona Heath ${ }^{2}$

“OK, let's leave it at that then"-an unexpected response from a man who has just been told his chest pain is unlikely to come from his heart. Before the pandemic, it was more common to hear, "I still want to know for sure." A few hours later, another unexpected response from a radiologist about an incidental finding on a computed tomography (CT) scan of the abdomen of a young woman: "very unlikely to be significant-you don't have to do a control CT." A comment rarely heard from a radiologist before covid-19 turned our world upside down.

We have seen many examples of when such hands-off approaches, as a direct result of the pandemic, have been beneficial to our patients: a man whose knee replacement surgery was postponed and who got so much better he no longer needed surgery; a woman whose headache improved during the prolonged waiting time for a CT scan that could thus be cancelled; a man with abdominal pain who would have been referred to the emergency department but was not because of the fear of covid-19 and then recovered spontaneously. Would the man who avoided knee surgery have had a serious complication with lifelong disability? Would the woman who avoided a CT scan have had an incidental finding with subsequent cascades of interventions with doubtful benefit and possible harm? Would the man who was not sent to the emergency department have undergone unnecessary explorative laparoscopy? Probably not in these cases-but certainly in some.

We have also seen tragic cases when patients have not received essential care for non-covid-19-related conditions: a man waiting an unacceptably long time for a colonoscopy for symptoms indicating cancer; a woman waiting too long to see a psychiatrist for grievous psychotic symptoms; an older woman with dementia fading away and eventually dying from "depression" caused by the rules about isolation from loved ones in nursing homes. The strong focus on covid-19 has indeed had high costs. But this text is about the potential of the pandemic to contribute to a much needed shift away from defensive medicine. We argue that covid-19 has helped doctors, patients, policy makers, and the public to understand, much more clearly than ever before, that hospitals can sometimes be dangerous places, and not a resource to use lightly.

There is an increasing recognition that defensive medicine threatens the health of people and the sustainability of health systems. ${ }^{1-3}$ Unnecessary tests, treatments, and diagnoses bring direct harm to people through adverse effects of interventions, psychosocial impacts of labelling, and overwhelming burden of treatment..$^{-5}$ Overuse and overdiagnosis also consume scarce resources, leading to underuse and underdiagnosis in other areas, which indirectly harm patients and lead to increased inequity. ${ }^{6}$ Healthcare spending grows all over the world, with poor correlation between increased costs and improved health in high income countries. ${ }^{78}$ The increasing costs of healthcare also draw resources from other societal sectors capable of improving health and wellbeing for the population. ${ }^{9}$

The reasons behind this development are multifaceted with vested interests playing a crucial role. ${ }^{10}$ But we should not underestimate the power of culture; all the way from medical school, to the consultation, to informal collegial discussions, to the science underpinning our efforts-medicine is permeated by a bias towards doing something rather than nothing, even when it may do more harm than good to our patients. Doctors failing to diagnose are resented and sometimes punished, while doctors who cause suffering through overdiagnosis and overtreatment are not. The consequence is an often irrational quest to find "the cause" of every symptom and to exclude every possibility of serious disease even when the probability is extremely small. Much too seldom do we consider the potential harm for our patients of those investigations that we do "just in case.” Expectations from patients and a fear of being sued are reasons often given as excuses. This may be true, but the anxiety of the doctor as a driver of defensive medicine should not be underestimated.

Central to this culture is a failure to manage uncertainty wisely. Uncertainty will always be inherent to the practice of medicine. Not even endless biomedical progress can change this. We are engaged in an imperious and foolish fight-striving to gain control and obliterate uncertainty at all costs. Yet the sudden shift in culture during these past months is apparent in our clinics. The threat of this terrible virus has made us take a step back and critically reflect on our priorities and our actions. We have suddenly begun to enact what we have known for a long time from experiences in palliative medicine: the importance of carefully considering the benefits and harms of every intervention and diagnosis-not just in terms of biomedical outcomes but also in the social, psychological, and existential experience of the patient. Every medical intervention and diagnosis should bring something meaningful to the patient. This pandemic has caused brutal suffering-but it may also help us improve our unsettled relationship with uncertainty.

Competing interests: We have read and understood BMJ policy on declaration of interests and have no relevant interests to declare. 
All authors write as individuals rather than as representatives of the organisations they work for.

Not commissioned, not peer reviewed

1 Pearson M. Tackling Wasteful Spending on Health. OECD. 10 January 2017. www.oecd.org/health/tackling-wasteful-spending-on-health-9789264266414-en.htm.

2 Shrank WH, Rogstad TL, Parekh N. Waste in the US health care system: estimated costs and potential for savings. JAMA 2019;322:1501-9. doi: 10.1001/jama.2019.13978 pmid: 31589283

3 Morgan DJ, Dhruva SS, Coon ER, Wright SM, Korenstein D. 2019 Update on medical overuse: a review. JAMA Intern Med 2019:179:1568-74.

doi: 10.1001/jamainternmed.2019.3842 pmid: 31498374

4 Cotter AR, Vuong K, Mustelin L, et al. Do psychological harms result from being labelled with an unexpected diagnosis of abdominal aortic aneurysm or prostate cancer through screening? A systematic review. BMJ Open 2017;7:e017565.

doi: 10.1136/bmjopen-2017-017565 pmid: 29237653

5 May C, Montori VM, Mair FS. We need minimally disruptive medicine. BMJ2009;339:b2803. doi: 10.1136/bmj.b2803 pmid: 19671932

6 Glasziou P, Straus S, Brownlee S, et al. Evidence for underuse of effective medical services around the world. Lancet 2017;390:169-77. doi: 10.1016/S0140-6736(16)30946-1 pmid: 28077232

7 OECD. Fiscal sustainability of health systems: bridging health and finance perspectives. 24 September 2015. www.oecd.org/publications/fiscal-sustainability-of-health-systems9789264233386-en.htm.

8 Guyatt GH, Devereaux P, Lexchin J, et al. A systematic review of studies comparing health outcomes in Canada and the United States. Open Med 2007;1:e27-36.pmid: 20101287

9 Marmot M, Allen J, Bell R, Bloomer E, Goldblatt PConsortium for the European Review of Social Determinants of Health and the Health Divide. WHO European review of social determinants of health and the health divide. Lancet 2012;380:1011-29. doi: 10.1016/S0140-6736(12)61228-8 pmid: 22964159

10 Moynihan R, Bero L, Hill S, et al. Pathways to independence: towards producing and using trustworthy evidence. BMJ2019;367:16576. doi: 10.1136/bmj.16576 pmid: 31796508 